\title{
8
}
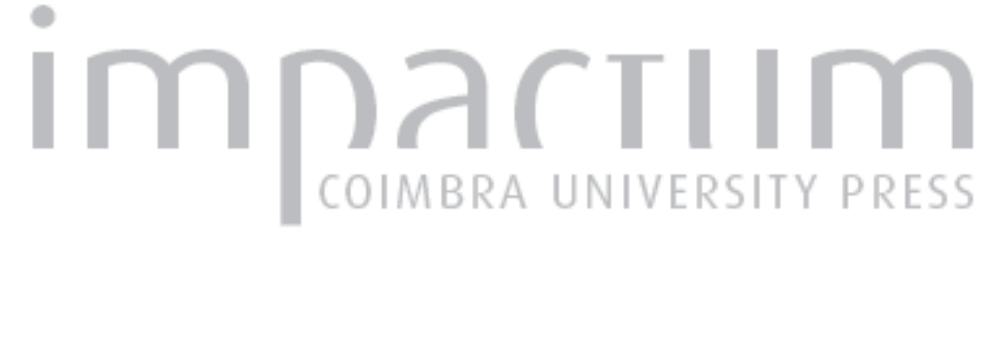

\section{Atividades culturais 2015-2016}

Publicado por: Imprensa da Universidade de Coimbra

URL

persistente:

URI:http://hdl.handle.net/10316.2/43034

DOI:

DOI:https://doi.org/10.14195/1647-8436_46_47_12

Accessed : $\quad$ 26-Apr-2023 09:53:24

A navegação consulta e descarregamento dos títulos inseridos nas Bibliotecas Digitais UC Digitalis, UC Pombalina e UC Impactum, pressupõem a aceitação plena e sem reservas dos Termos e Condições de Uso destas Bibliotecas Digitais, disponíveis em https://digitalis.uc.pt/pt-pt/termos.

Conforme exposto nos referidos Termos e Condições de Uso, o descarregamento de títulos de acesso restrito requer uma licença válida de autorização devendo o utilizador aceder ao(s) documento(s) a partir de um endereço de IP da instituição detentora da supramencionada licença.

Ao utilizador é apenas permitido o descarregamento para uso pessoal, pelo que o emprego do(s) título(s) descarregado(s) para outro fim, designadamente comercial, carece de autorização do respetivo autor ou editor da obra.

Na medida em que todas as obras da UC Digitalis se encontram protegidas pelo Código do Direito de Autor e Direitos Conexos e demais legislação aplicável, toda a cópia, parcial ou total, deste documento, nos casos em que é legalmente admitida, deverá conter ou fazer-se acompanhar por este aviso. 


\section{BOLETIM DA \\ BIBLIOTECA GERAL DA UNIVERSIDADE DE COIMBRA}

VOL. 46/47 (2015/2016)

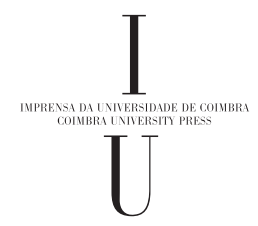




\section{Atividades culturais 2015-2016}

A Biblioteca Geral acolhe regularmente nos seus espaços diversos tipos de realizações de caráter cultural.

No decurso dos anos de 2015 e 2016, foram organizadas diversas exposições, colóquios, palestras, conferências e concertos. Tratou-se de iniciativas promovidas quer pela BGUC, quer por outras entidades dependentes da Universidade ou a ela associadas. Foram realizados na Sala do Catálogo, na Sala de S. Pedro e na Biblioteca Joanina (Piso Nobre e Piso intermédio). De entre as várias atividades realizadas neste período, destacam-se, em seguida, aquelas que se revestiram de maior relevo e impacto. Os catálogos das exposições bibliográficas encontram-se em Anexo.

\section{Sala do Catálogo}

\section{Exposições}

1.1. - Exposição comemorativa do Centenário da $1^{a}$ Grande Guerra, realizada entre os dias 10 de novembro de 2014 e 5 de janeiro de 2015. Incluiu livros, jornais, revistas, e ainda fotografias da época pertencentes ao espólio da Biblioteca da Geral.

1.2. - Exposição A "Peregrinação" de Fernão Mendes Pinto: O Livro do Deslumbramento, comemorando o quarto centenário da publicação desse livro singular. De entre as mais de 167 edições publicadas, 
foram expostas as de texto integral, preparadas por Brito Rebelo, Jordão de Freitas, Costa Pimpão e César Pegado, Adolfo Casais Monteiro, António José Saraiva, Maria Alberta Meneres e Aníbal Pinto de Castro. Foram igualmente exibidas as versões abreviadas e adaptações de José Tavares, Aquilino Ribeiro, António Sérgio, Rodrigues Lapa, Branquinho da Fonseca, Adolfo Casais Monteiro, sucessivamente reeditadas ao longo do século XX. O Catálogo da exposição encontra-se em Anexo.

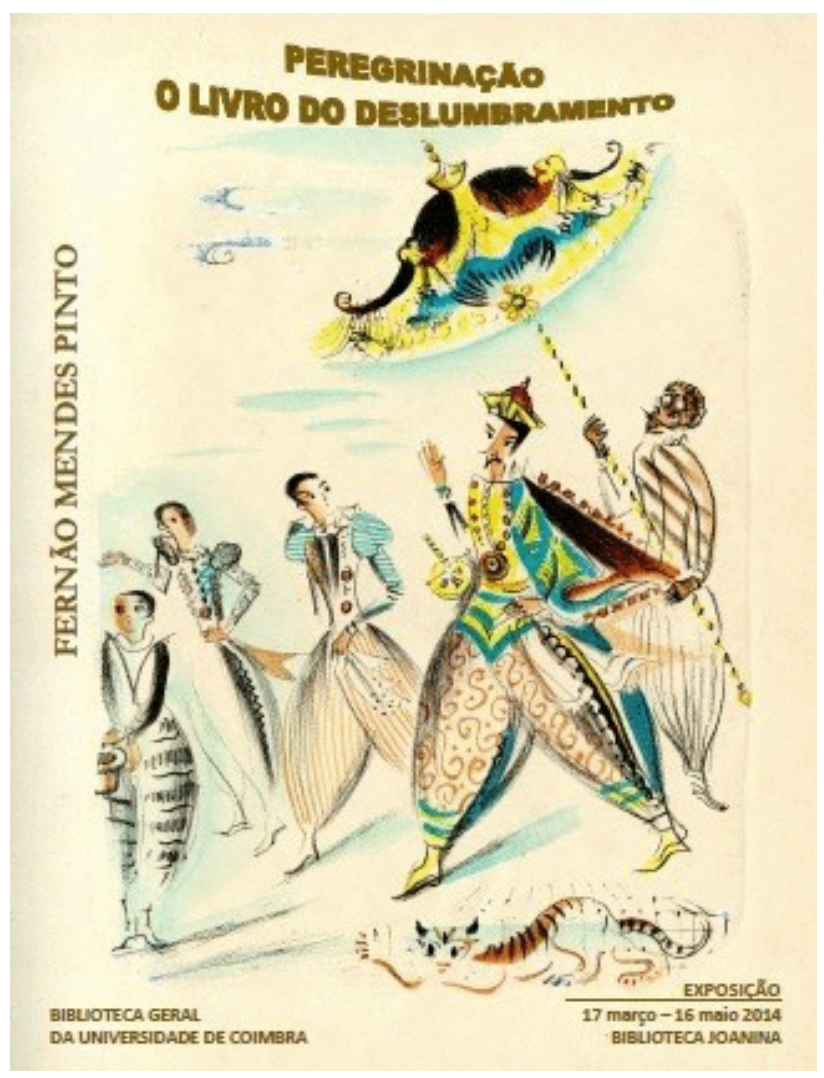

Cartaz da exposição bibliográfica Peregrinação: O Livro do Deslumbramento.

Esta exposição, inicialmente patente na Biblioteca Joanina, de março a junho de 2014, transitou depois para a Sala do Catálogo, onde esteve presente ao longo do mês de janeiro de 2015. 


\section{3. - Exposição evocativa Vida e Obra de T. S Eliot (1888-1965).}

Reconhecido como uma das maiores figuras da literatura inglesa, este escritor foi agraciado com diversos prémios, destacando-se o prémio Nobel de Literatura em 1948, o Hanseatic Goethe Prize (Hamburgo,1955) e a Dante Medal (Florença, 1959). A exposição esteve patente de fevereiro a março 2015, na evocação do cinquentenário da morte do escritor. O Catálogo da exposição bibliográfica encontra-se em Anexo.

1.4. - Exposição comemorativa dos 250 anos do nascimento de Bocage, intitulada Bocage (1765-1805): 250 anos do seu nascimento. Foi considerado o mais importante poeta português do século XVIII e um dos maiores sonetistas líricos da literatura portuguesa, na linha de Camões e precedendo Antero de Quental. Das obras expostas destacamos as seguintes: Elegia, que o mais ingenuo, e verdadeiro sentimento consagra à deplorável morte do illustrissimo, e excellentissimo senhor D. Jozé Thomaz de Menezes, [...], de 1790; Queixumes do pastor Elmano contra a falsidade de pastora Urselina: écloga, de 1791; Epicedio na sentida morte do [...] Senhor D. Pedro José de Noronha, Marquez de Angeja [...], de 1804; Rimas de Manoel Maria de Barbosa du Bocage. Segunda edição, correcta, e aumentada, de 1800; Rimas de Manoel Maria de Barbosa du Bocage dedicadas à amizade, de 1802; Poesias dedicadas à IIIma ., e Exma . Senhora Condessa de Oyenhausen, de 1804 e A saudade materna : idyllio, na prematura, e chorada morte da Senhora Dona Anna Raimunda Lobo [...], de 1805. Esta exposição esteve patente de 28 de abril a 29 de maio de 2015. Ver o Catálogo em Anexo.

1.5. - Exposição comemorativa do VI Centenário da Tomada de Ceuta em 21 de agosto de 1415, de 22 de julho a 4 de setembro. $O$ Catálogo encontra-se publicado em Anexo.

1.6. - Mostra bibliográfica intitulada Fernando Pessoa: os rostos plurais. Destacaram-se as obras publicadas em vida do escritor, 35 
Sonnets e Antinous, ambas em 1918, English Poems, em 1921 e Mensagem, em 1934, obra premiada pelo Secretariado de Propaganda Nacional. Esteve patente de 28 de setembro a 4 dezembro na Sala do Catálogo, e na Biblioteca Joanina (Piso intermédio) de 15 de dezembro a 31 de janeiro de 2016. Catálogo em Anexo.

1.7. - Exposição documental intitulada Biblioalimentaria. Inte-

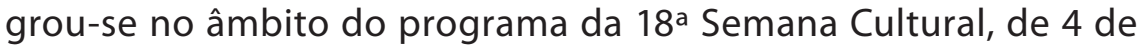
março a 1 de maio de 2016. Incluiu um ciclo de palestras que decorreu na Sala de S. Pedro, com duas sessões: "Cozinha à Portugueza pelas mãos de um francês: Lucas Rignaud e o património culinário português", por João Pedro Gomes, e "A Universidade de Coimbra no cardápio da Cosinha Portugueza de 1902: uma história por contar", pela Professora Doutora Carmen Soares.

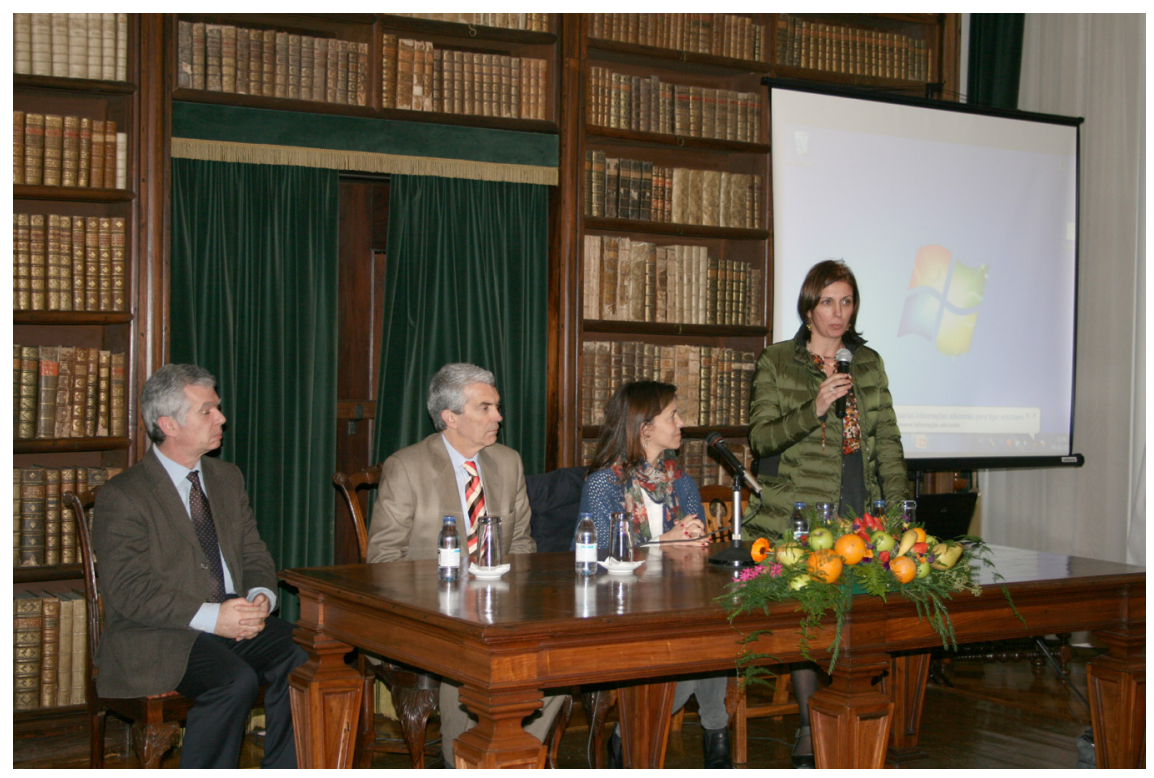

Sessão na Sala de S. Pedro no âmbito da exposição Biblioalimentaria: Professor Doutor José Augusto Cardoso Bernardes, Diretor da Biblioteca Geral; Professor Doutor José Pedro Paiva, Diretor da Faculdade de Letras; Clara Almeida Santos, Vice-Reitora da UC; Professora Doutora Carmen Soares. 
1.8. - Exposição William Shakespeare (1564-1616). A mostra beneficiou da colaboração da Professora Doutora Adriana Bebiano, da Faculdade de Letras da Universidade de Coimbra, que elaborou um texto para o efeito, intitulado: "O que é que Shakespeare tem que é diferente dos outros?". Ver o Catálogo em Anexo.

1.9. - Exposição bibliográfica e documental: Joaquim de Carvalho. Foi organizada pelo Departamento de Cultura da Câmara Municipal da Figueira da Foz. Retrato da vida e obra de Joaquim de Carvalho (Figueira da Foz, 10 de junho de 1892 - Coimbra, 27 de outubro de 1958). Joaquim de Carvalho foi professor da Faculdade de Letras da Universidade de Coimbra, onde regeu cadeiras de Filosofia e de História da Cultura. Foi ainda diretor da Revista da Universidade de Coimbra, da Biblioteca Geral (1926-1931) e da Imprensa da Universidade.

A exposição, inaugurada no dia 13 de junho de 2016, esteve patente até ao dia 30 de agosto. No dia da inauguração, o Doutor Paulo Archer de Carvalho, do CEIS20, proporcionou uma visita guiada.

1.10. - Exposição Mário de Sá-Carneiro (1890-1916), assinalando o primeiro centenário da morte do autor. Além de exemplares da sua obra (com destaque para algumas primeiras edições) e de um pequeno conjunto de bibliografia crítica, estiveram expostos a certidão de batismo redigida em Lisboa, o registo académico da passagem de Sá-Carneiro por Coimbra e a petição de matrícula no $1^{\circ}$ ano de Direito (gentilmente cedidos, pelo Arquivo da Universidade).

Foram também exibidos alguns livros e cadernos escolares, usados pelo jovem Sá-Carneiro enquanto estudante liceal, com curiosas anotações autógrafas sobre colegas e professores. O interesse dos documentos (que hoje pertencem à Biblioteca) relaciona-se ainda com a presença de alguns versos soltos, que viriam depois a ser incorporados na sua obra publicada. Esteve patente de 12 de setembro a 28 de outubro. O Catálogo da exposição encontra-se em Anexo. 


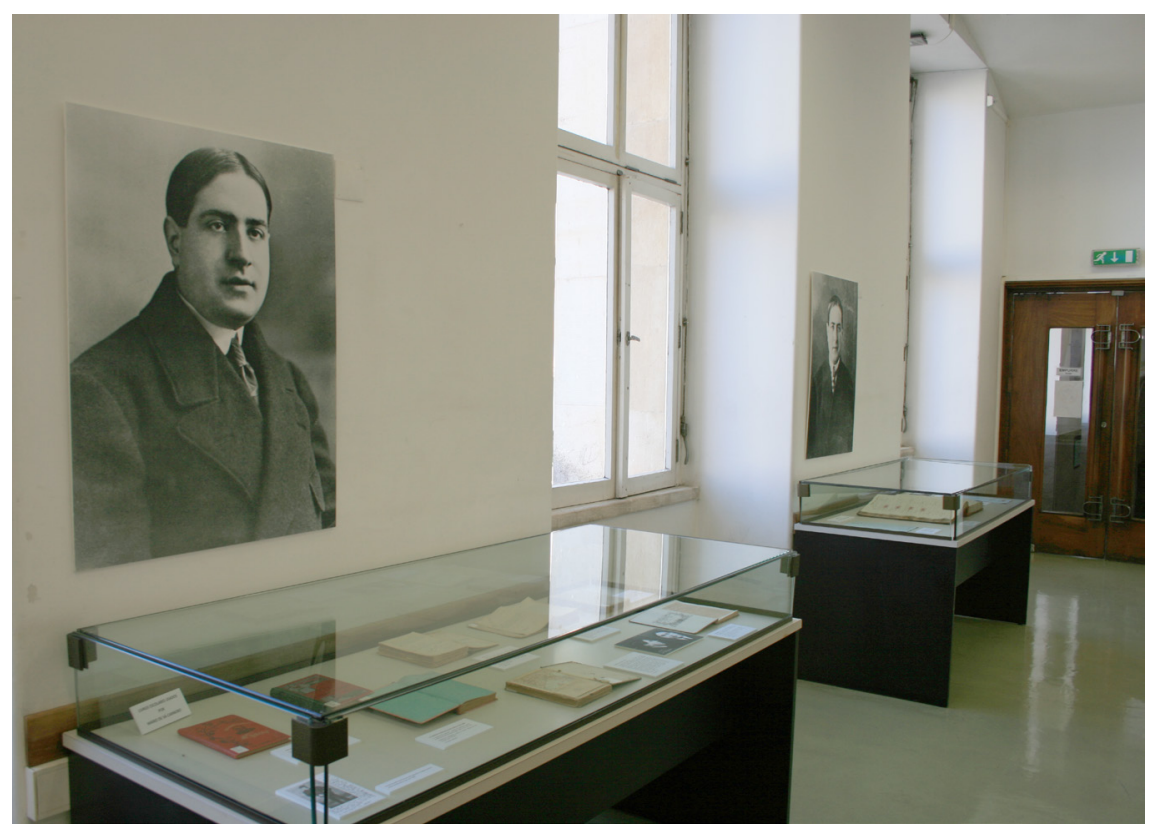

Fotografia da exposição sobre Mário de Sá-Carneiro na Sala do Catálogo.

\section{Sala de S. Pedro}

\section{A - Exposições}

2.1. - No âmbito da $18^{a}$ Semana Cultural da Universidade de Coimbra (1 de março a 1 de maio de 2016), subordinada ao tema "O livro: no princípio era o conhecimento", a BGUC apresentou, de 2 de março a 29 de abril, uma exposição bibliográfica ilustrativa da evolução e metamorfoses do suporte livro: Livro/códice: do séc. XII ao XXI - Upgrading since 1150, desde o códice em pergaminho até ao livro eletrónico. 


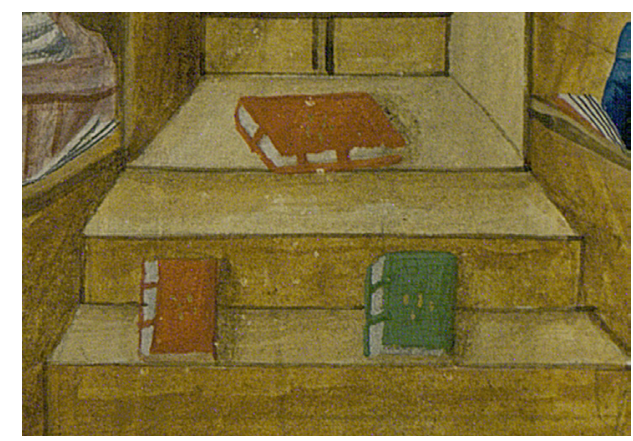

Excerto do Manuscrito 723 que ilustrou a notícia da exposição Livro/Códice do séc. XII ao XXI.

Na mostra incluíam-se manuscritos, com particular destaque para um exemplar da Bíblia atlântica, alguns incunábulos, como a Bíblia das 48 linhas e a Crónica de Nuremberga, livros raros como a Vita Christi e a Bíblia poliglota de Alcalá. De entre o núcleo de livros impressos foi dado particular relevo aos livros ilustrados, através de diversas técnicas como a xilogravura, a gravura em cobre ou aço, ou a estampagem por meio de técnicas como mezzotinto e a aquatinta, bem como à evolução do suporte papel.

2.2. - Exposição A Polifonia em Santa Cruz de Coimbra. Integrou-se no âmbito do Ciclo de Conferências Ilustradas do Coro Dom Pedro de Cristo, de 2 de maio a 1 de junho. A sessão de abertura contou com a participação do Padre Pedro Miranda (que proferiu uma palestra sobre o assunto) e do Coro Dom Pedro de Cristo, que interpretou temas da autoria do compositor.

\section{B - Lançamento e apresentação de obra}

- Lançamento da obra «Uma Autobiografia da Razão: A matriz filosófica da historiografia da cultura de Joaquim de Carvalho», da autoria de Paulo Archer de Carvalho, no dia 16 de junho de 2015. Contou com a apresentação do Professor Doutor Fernando Catroga. 


\section{C - Ciclo de Sessões a "Biblioteca Geral Mostra (e Explica) o seus Tesouros"}

Com o objetivo de dar a conhecer ao público alguns dos seus documentos mais preciosos, a Biblioteca levou a cabo um conjunto de sessões em 2015 que pretendiam não apenas mostrar mas também explicar as obras. As sessões tiveram uma periocidade mensal, decorreram aos sábados de manhã e envolveram a participação de bibliotecários e de especialistas da Universidade, nas diferentes matérias a que respeitavam os documentos. Foram apresentadas as seguintes obras:

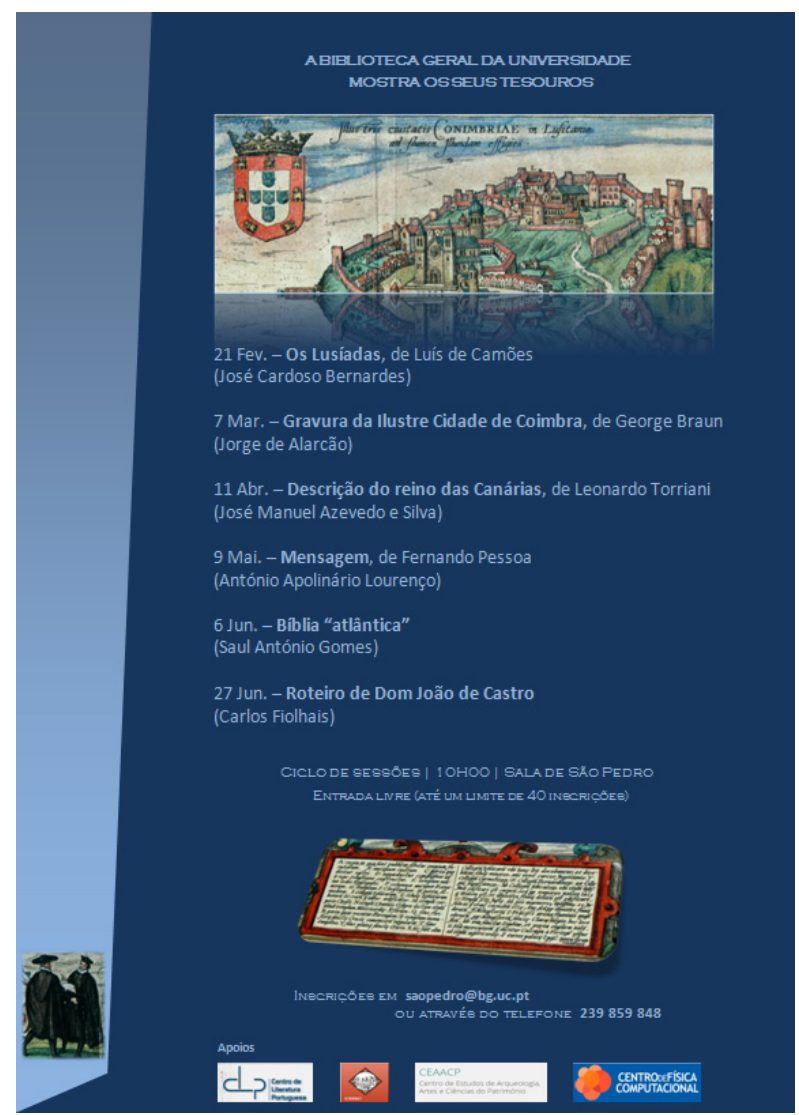

Cartaz do ciclo de sessões "A Biblioteca Geral da Universidade mostra (e explica) os seus tesouros". 
- No dia 21 de fevereiro, Os Lusíadas de Luís de Camões, obra impressa em Lisboa "em casa de Antonio Gõçaluez", em 1572. A apresentação esteve a cargo do Professor Doutor, José Augusto Bernardes, Diretor da Biblioteca Geral;

- No dia 7 de março a Gravura da Cidade de Coimbra (Illustris civitatis Conimbriae in Lusitania ad flumen Illundam effigies), retirada da obra "Civitates Orbis Terrarum" de George Braun e Frans Hogenberg, publicada em Coloniae Agrippinae, cerca de 1580. A apresentação foi dirigida pelo Professor Doutor Jorge de Alarcão;

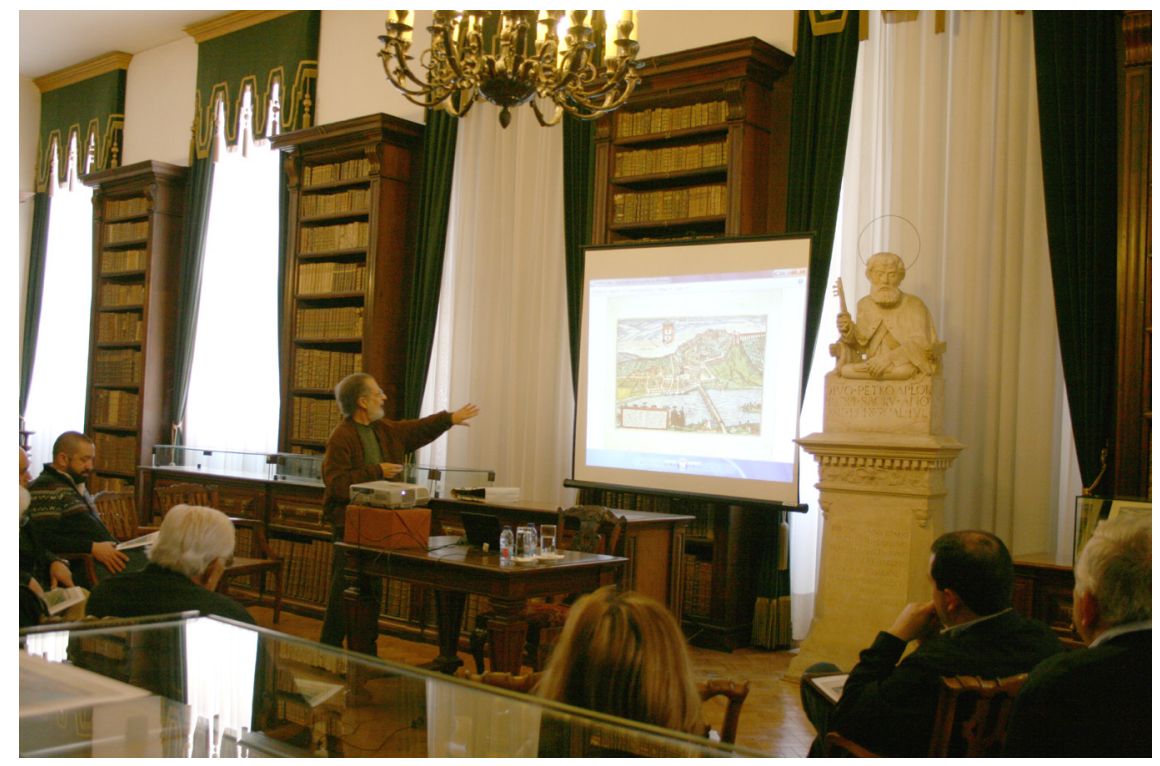

Sessão com o Professor Doutor Jorge de Alarcão sobre "A Gravura da Cidade de Coimbra".

- No dia 11 de abril, a Descrição do Reino das Canárias (Alla Maesta del Re Catolico, descrittione et historia del regno de I'isole Canarie gia dette le Fortvnate con il parere delle loro fortificationi), de Leonardo Torriani (1560-1628). O manuscrito do final do séc. XVI foi apresentado e explicado pelo Professor Doutor José Manuel de Azevedo e Silva; 
- No dia 9 de maio, a $1^{\text {a }}$ edição de Mensagem, obra de Fernando Pessoa (1888-1935), editada em Lisboa pela Parceria António Maria Pereira, em 1934. A apresentação esteve a cargo do Professor Doutor António Apolinário Lourenço;

- No dia 6 de junho, a Bíblia "atlântica", manuscrito em pergaminho, datável do último terço do século XII. A explicação do códice esteve a cargo do Professor Doutor Saúl António Gomes (Professor da Faculdade de Letras), especialista em paleografia e diplomática;

- No dia 27 de junho, Roteiro de D. João de Castro (Tavoas dos lugares da costa da India), manuscrito do séc. XVI. A apresentação desta obra esteve a cargo do Professor Doutor Carlos Fiolhais.

Em 2016, no segundo ciclo de sessões, foram apresentadas as seguintes obras:

- No dia 5 de março, foi apresentado pela Professora Doutora Maria José Azevedo Santos o Livro de Horas, manuscrito iluminado do séc. $\mathrm{XVl}$;

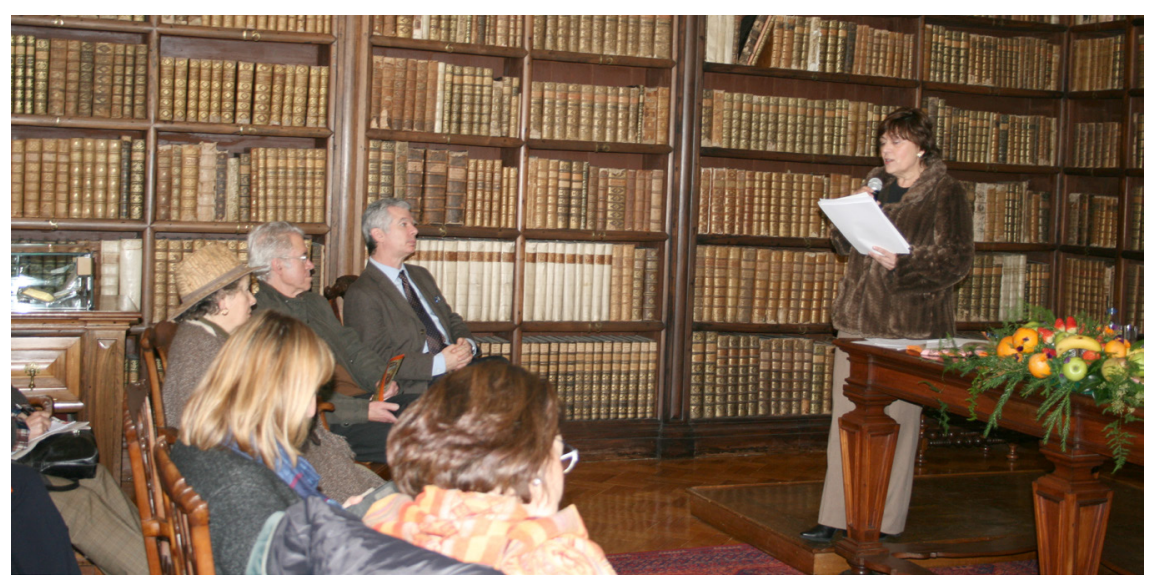

Sessão com a Professora Doutora Maria José Azevedo Santos sobre o "Livro de Horas". 
- No dia 2 de abril, foi apresentado pelo Professor Doutor José Augusto Cardoso Bernardes, Os Lusíadas, obra dirigida por Fernandes Costa, prefaciada por D. Antonio Mendes Bello e por Manuel Pinheiro Chagas, editada em Lisboa, por Silvestre Castanheiro, em 1898. Trata-se da edição autográfica de "Os Lusíadas", comemorativa do Quarto Centenário do Descobrimento da Índia;

- No dia 19 de março, O Livro de lembranças dos Planetas, manuscrito de 1593, apresentado pelo Professor Doutor António Olaio, Diretor do Colégio das Artes e artista plástico;

- No dia 12 de março, foi apresentada e explicada pelo Doutor Jorge Paiva, Professor de Botânica do Departamento das Ciências da Vida, Faculdade de Ciências e Tecnologia da Universidade de Coimbra a obra Éléments de botanique ou Méthode pour connaître les plantes (1694), de Joseph Pitton de Tournefort (1656-1708), botânico e médico francês. Foi publicada em Paris, na "I'imprimerie Royale : [par les soins de Jean Anisson]", em 1694.

\section{D - Colóquios}

- Congresso "Homenagem ao Embaixador Calvet de Magalhães", nos dias 13 e 14 de abril de 2015, promovido pelo CEIS20;

- "Jornadas Modernistas", comemorativas do centenário da publicação da revista Orpheu, promovidas pela Faculdade de Letras da Universidade de Coimbra. A intervenção do Professor Eduardo Lourenço, intitulada "Lourenço em Pessoa", realizou-se na Sala de S. Pedro, com a participação do Professor José Augusto Cardoso Bernardes e a moderação do Professor António Apolinário Lourenço; 


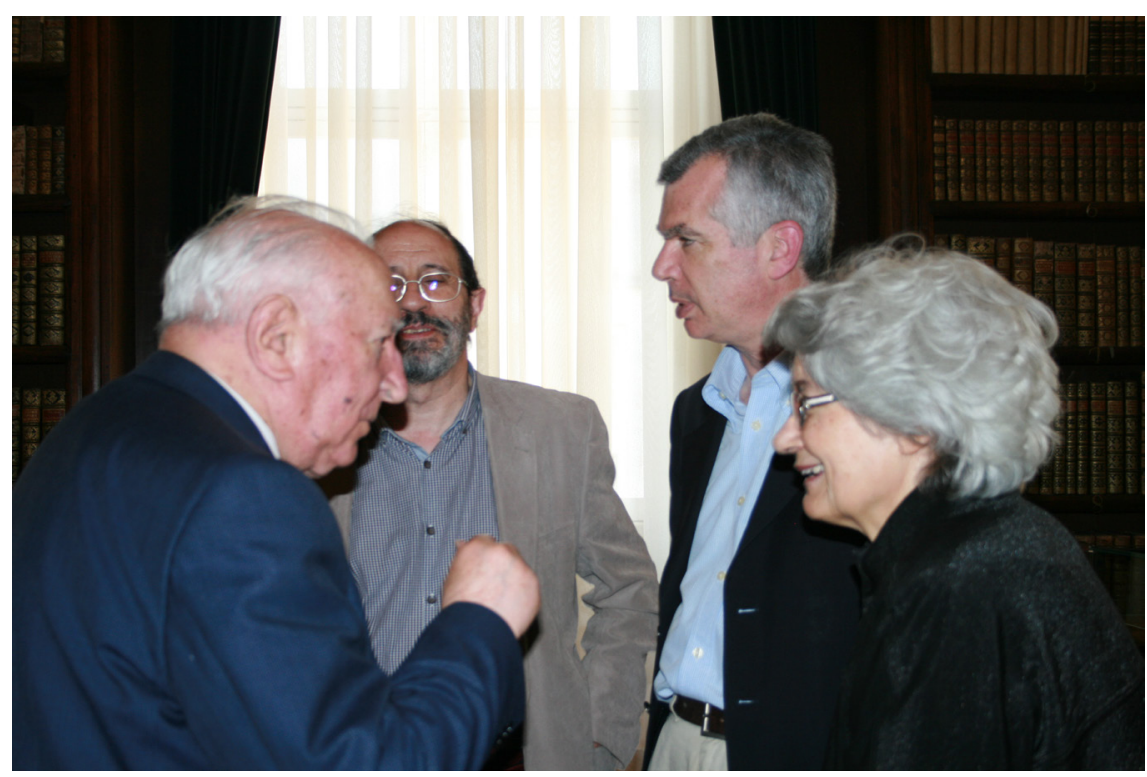

Sessão na Sala de S. Pedro no âmbito das "Jornadas Modernistas":

Professor Doutor Eduardo Lourenço, Professor Doutor Apolinário Lourenço, Professor Doutor José Augusto Cardoso Bernardes, Professora Doutora Ofélia Paiva Monteiro.

- Congresso "Europa, Atlântico, Mundo. Mobilidades, Crises, Dinâmicas Culturais. Pensar com Maria Manuela Tavares Ribeiro". Tratou-se de uma homenagem prestada à referida Professora da Faculdade de Letras, nos dias 17 e 18 de fevereiro de 2016;

- Colóquio "Portugal e a Europa: 30 Anos de Integração", numa parceria do Centro de Estudos Interdisciplinares do Século XX da Universidade de Coimbra - CEIS20 e do Gabinete do Parlamento Europeu em Portugal, nos dias 17 e 18 de março de 2016;

- Colóquio "40 anos da Constituição e das autonomias políticas regionais dos Açores e da Madeira", iniciativa e coordenação científica de Isabel Valente, do Centro de Estudos Interdisciplinares do Século XX da Universidade de Coimbra - CEIS20. O evento contou com a presença dos Doutores Alberto João Jardim e João Bosco 
Mota Amaral, dos Professores Jorge Miranda e Vital Moreira, e das deputadas ao Parlamento Europeu Cláudia Monteiro e Sofia Ribeiro, no dia 23 de maio de 2016;

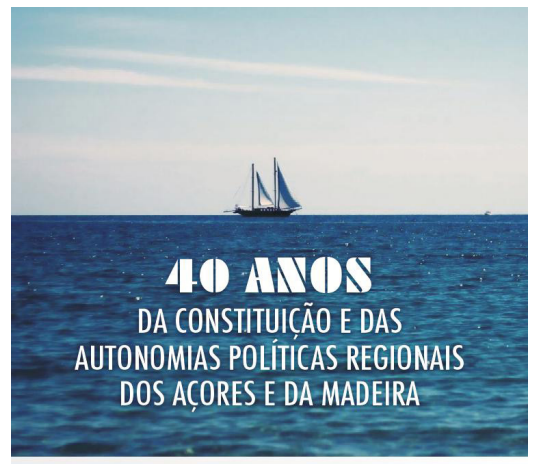

23 de maio de 2016

SALA DE SÄO PEDRO DA BBBLIOTECA GERAL DA UNVERSIDADE DE COMBBRA

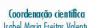

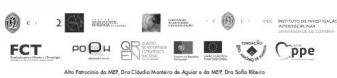

Cartaz do Colóquio realizado na Sala de S. Pedro sobre autonomia regional.

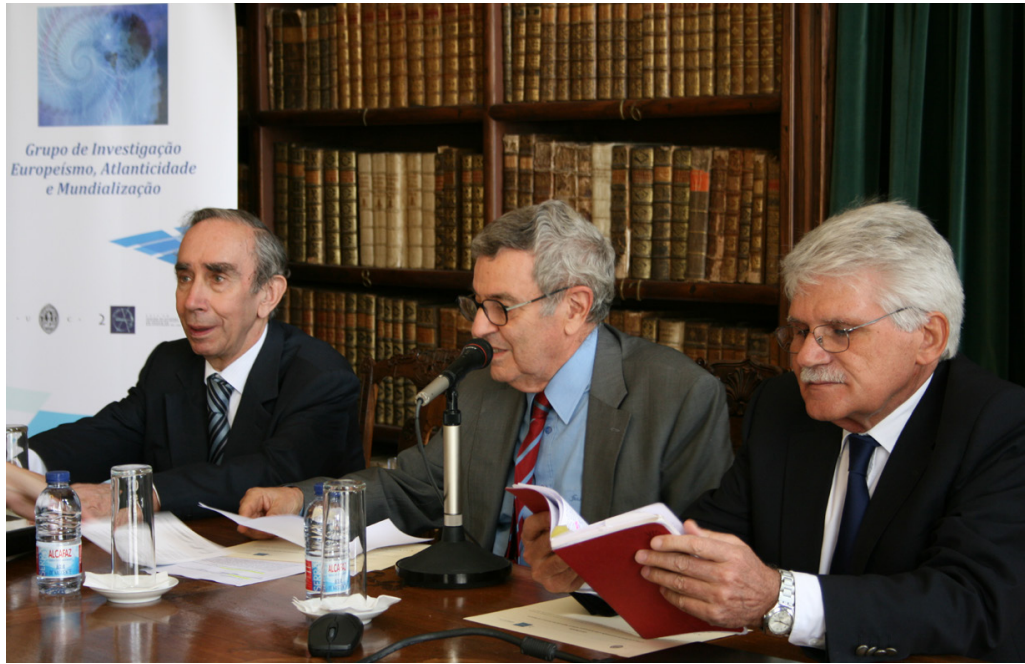

Colóquio "40 anos da Constituição e das autonomias políticas regionais dos Açores e da Madeira": Professor Doutor Jorge Miranda; Professor Doutor Manuel Lopes Porto; Professor Doutor Vital Morreira. 
- "Clavis Bibliothecarum: Novas Chaves de Investigação", foi o título da sessão de apresentação da obra "Clavis Bibliothecarum: Catálogos e Inventários de Livrarias de Instituições Religiosas em Portugal até 1834", realizada no dia 29 junho 2016. Resultado de um vasto trabalho de investigação desenvolvido por Luana Giurgevich e Henrique Leitão entre os diversos fundos monásticos nacionais. Trata-se do mais completo levantamento de catálogos e inventários de bibliotecas de instituições religiosas realizado em Portugal, dos séculos X a XIX, descrevendo cerca de um milhar de listas de livros e várias centenas de documentos inéditos referentes ao funcionamento e vida das antigas livrarias eclesiásticas;

- No dia 18 de outubro 2016, reunião científica para assinalar o “Dia Europeu contra o Tráfico de Pessoas, instituído em 2007 pela Comissão Europeia", com o objetivo de dar visibilidade às ações que têm vindo a ser desenvolvidas no sentido de aprofundar conhecimentos e sensibilizar os profissionais e o público em geral quanto à prevenção, combate e repressão deste tipo de criminalidade altamente organizada na Europa.

A organização desta reunião pertenceu ao Grupo de Investigação Europeísmo, Atlanticidade e Mundialização do CEIS20-UC e ao Instituto Jurídico, procurando uma abordagem de forma interdisciplinar.

\section{Biblioteca Joanina}

\section{A - Exposições}

- Exposição Gravuras de Coimbra, de 26 de março a 15 de maio de 2015, no Piso Intermédio, com o objetivo de mostrar a evolução da representação da cidade de Coimbra, desde o séc. XVI ao início do séc. XX. Ver o Catálogo em Anexo. 
- Mostra bibliográfica de ilusionismo e magia, para apoio ao evento A UC Mágica de Luís de Matos, no âmbito do ciclo "7 séculos, 7 personalidades, 7 histórias", no dia 30 de maio de 2015.

- De 9 de junho a 31 de agosto de 2015, no Piso intermédio esteve patente a Exposição A Biblioteca Geral da Universidade e a "Marca do Património Europeu", na sequência da atribuição à Biblioteca Geral da Marca do Património Europeu.

- Exposição evocativa 400 anos da morte de Miguel de Cervantes (1547-1616). Esta exposição integrou um conjunto importante de obras cervantinas do séc. XVII, envolvendo também traduções para português (e outras línguas), de 5 abril a 31 de maio. Ver O Catálogo em Anexo.

- Exposição Conimbriga Urbe ad Orbem, de 7 julho a 30 outubro, lembrando alguns dos milhares de Irmãos e Padres que, formados ou apenas tendo passado por Coimbra, se espalharam por todo o mundo. O Catálogo da exposição bibliográfica encontra-se em Anexo.

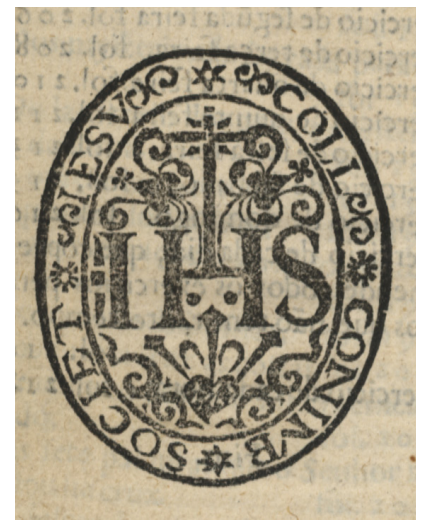




\section{B - Lançamento de obras}

- No dia 18 de dezembro de 2015, dando continuidade ao projeto iniciado em 2014 da reprodução fac-similada de "Farmacopeias Portuguesas", foi apresentado o "Codigo Pharmaceutico Lusitano, ou Tratado de Pharmaconomia", no âmbito da coleção, com o patrocínio exclusivo da Bluepharma - Indústria Farmacêutica, SA. A apresentação da obra esteve a cargo do Doutor João Rui Pita.

\section{C - Concertos}

Dentro das atividades desenvolvidas pela Vice-Reitoria da Cultura em colaboração com a BGUC, realizaram-se os seguintes concertos:

- Concerto no âmbito do projeto Itália - Portugal - Brasil : Uma viagem sonora, no dia 20 de fevereiro de 2015;

- Concerto de Piano e Flauta, integrado no Programa das Comemorações dos 725 anos da Universidade de Coimbra, no dia 4 de março de 2015;

- Concerto pela pianista Lícia Lucas (projeto Música no Museu), no dia 6 de março;

- Concerto pela pianista Maria Helena de Andrade (projeto Música no Museu), no dia 30 de junho de 2015;

- Concerto pela pianista Kiana Shafiei - Músicas do Mundo: Entre a Tradição e o Modernismo, no dia 16 de julho de 2015;

- Concerto pela pianista Licia Lucas (projeto Música no Museu), no dia 10 de setembro de 2015; 
- Onda de Silêncio - Recital de Canto e Guitarra, com Deborah Oliveira (Canto) e Eduardo Barretto (Guitarra), no dia 16 fevereiro de 2016;

- Concerto pela pianista brasileira Ana Maria Brandão (projeto Música no Museu), no dia 30 de março de 2016;

- Concerto-Reflexão em Sexta-feira Santa, no dia 25 de março de 2016, para o Fundo Solidário (de apoio aos estudantes carenciados), organizado em colaboração com a Capelania da Universidade de Coimbra e o Instituto Missionário do Sagrado Coração - Dehonianos;

- Concerto de piano por Carlos Bianchini, no dia 13 de maio de 2016;

- Concerto pelo pianista brasileiro Diego Caetano, no dia 27 de maio 2016;

- Concerto pela pianista Ana Maria Brandão (projeto Música no Museu), no dia 9 de junho de 2016;

- Concerto pela cantora e compositora brasileira Cláudia Ramos (projeto Música no Museu), acompanhada pelo violonista, compositor e produtor musical Victor Ribeiro e o pianista Francisco Pellegrini, no dia 9 de setembro de 2016.

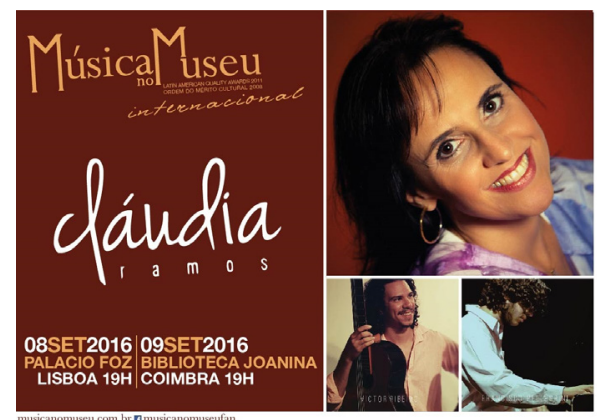

Flyer do concerto de Cláudia Ramos. 